\title{
Erratum to: A new method for interval estimation of the mean of the Gamma distribution
}

\author{
H. V. Kulkarni · S. K. Powar
}

Published online: 13 December 2009

(C) Springer Science+Business Media, LLC 2009

\section{Erratum to: Lifetime Data Anal DOI 10.1007/s10985-009-9142-4}

The author regrets for an error occurred in the Acknowledgement section of the article.

The correct version of the acknowledgement is as given below:

Acknowledgements We are very much grateful to anonymous referees and the Associated Editor for many constructive suggestions that greatly improved the manuscript. H. V. Kulkarni was supported by the grants received by Government of India, Department of Science and Technology, India, under the project Reference No. SR/S4/MS: 306/05.

The online version of the original article can be found under doi:10.1007/s10985-009-9142-4.

H. V. Kulkarni $(\varangle) \cdot$ S. K. Powar

Department of Statistics, Shivaji University, Kolhapur, India

e-mail: kulkarnih1@rediffmail.com

S. K. Powar

e-mail: sarjerao.powar@rediffmail.com 